\title{
Dental and skeletal changes in patients with mandibular retrognathism following treatment with Herbst and pre- adjusted fixed appliance
}

\author{
Fabio de Abreu Vigorito1, Gladys Cristina Dominguez², Luís Antônio de Arruda Aidar ${ }^{3}$
}

Objective: To assess the dentoskeletal changes observed in treatment of Class II, division 1 malocclusion patients with mandibular retrognathism. Treatment was performed with the Herbst orthopedic appliance during 13 months (phase I) and pre-adjusted orthodontic fixed appliance (phase II). Methods: Lateral cephalograms of 17 adolescents were taken in phase I onset $\left(\mathrm{T}_{1}\right)$ and completion $\left(\mathrm{T}_{2}\right)$; in the first thirteen months of phase II $\left(\mathrm{T}_{3}\right)$ and in phase II completion $\left(\mathrm{T}_{4}\right)$. Differences among the cephalometric variables were statistically analyzed (Bonferroni variance and multiple comparisons). Results: From $\mathrm{T}_{1}$ to $\mathrm{T}_{4}, 42 \%$ of overall maxillary growth was observed between $\mathrm{T}_{1}$ and $\mathrm{T}_{2}(\mathrm{P}$ $<0.01$ ), $40.3 \%$ between $\mathrm{T}_{2}$ and $\mathrm{T}_{3}(\mathrm{P}<0.05)$ and $17.7 \%$ between $\mathrm{T}_{3}$ and $\mathrm{T}_{4}$ (n.s.). As for overall mandibular movement, 48.2\% was observed between $\mathrm{T}_{1}$ and $\mathrm{T}_{2}(\mathrm{P}<0.001)$ and $51.8 \%$ between $\mathrm{T}_{2}$ and $\mathrm{T}_{4}(\mathrm{P}<0.01)$ of which $15.1 \%$ was observed between $\mathrm{T}_{2}$ and $\mathrm{T}_{3}$ (n.s.) and $36.7 \%$ between $\mathrm{T}_{3}$ and $\mathrm{T}_{4}(\mathrm{P}<0.01)$. Class II molar relationship and overjet were properly corrected. The occlusal plane which rotated clockwise between $\mathrm{T}_{1}$ and $\mathrm{T}_{2}$, returned to its initial position between $\mathrm{T}_{2}$ and $\mathrm{T}_{3}$ remaining stable until $\mathrm{T}_{4}$. The mandibular plane inclination did not change at any time during treatment. Conclusion: Mandibular growth was significantly greater in comparison to maxillary, allowing sagittal maxillomandibular adjustment. The dentoalveolar changes (upper molar) that overcorrected the malocclusion in phase I, partially recurred in phase II, but did not hinder correction of the malocclusion. Facial type was preserved.

Keywords: Angle Class II malocclusion. Orthopedics. Orthodontics.

Objetivo: avaliar as alterações dentoesqueléticas observadas no tratamento da má oclusão de Classe II com retrognatismo mandibular, realizado com aparelho ortopédico de Herbst durante 13 meses (Fase I) e aparelho ortodôntico fixo pré-ajustado (Fase II). Métodos: foram obtidas telerradiografias laterais de 17 adolescentes, ao início $\left(\mathrm{T}_{1}\right)$, final da Fase $\mathrm{I}\left(\mathrm{T}_{2}\right)$, primeiros 13 meses da Fase II $\left(\mathrm{T}_{3}\right)$ e término da Fase II $\left(\mathrm{T}_{4}\right)$. As diferenças entre as variáveis cefalométricas foram analisadas estatisticamente (variância e comparações múltiplas de Bonferroni). Resultados: de $\mathrm{T}_{1}$ a $\mathrm{T}_{4}$, do total da projeção da maxila, $42 \%$ foram observados de $\mathrm{T}_{1}$ a $\mathrm{T}_{2}(\mathrm{p}<0,01) ; 40,3 \%$ de $\mathrm{T}_{2}$ a $\mathrm{T}_{3}(\mathrm{p}<0,05)$; e 17,7\% de $\mathrm{T}_{3}$ a $\mathrm{T}_{4}$ (n.s.). Do total da projeção da mandíbula, foi notado $48,2 \%$ de $\mathrm{T}_{1}$ a $\mathrm{T}_{2}$ ( $\mathrm{p}<0,001$ ) e $51,8 \%$ de $\mathrm{T}_{2}$ a $\mathrm{T}_{4}(\mathrm{p}<0,01)$, sendo $15,1 \%$ (n.s.) de $\mathrm{T}_{2}$ a $\mathrm{T}_{3}, \mathrm{e} 36,7 \%$ de $\mathrm{T}_{3}$ $\mathrm{a} \mathrm{T}_{4}(\mathrm{p}<0,01)$. A relação molar e a sobressaliência foram corrigidas idealmente. Em $\mathrm{T}_{4}$, todos apresentavam características de oclusão normal. O plano oclusal que de $\mathrm{T}_{1}$ a $\mathrm{T}_{2}$ rotacionou no sentido horário, de $\mathrm{T}_{2}$ a $\mathrm{T}_{3}$ retornou aos valores iniciais, mantendo-se estável até $\mathrm{T}_{4}$. A inclinação do plano mandibular, responsável pela caracterização do tipo facial, não alterou em nenhum tempo. Conclusão: a mandíbula cresceu significativamente mais que a maxila, favorecendo o ajuste sagital maxilomandibular. As mudanças dentárias (molares superiores), que sobrecorrigiram a má oclusão na Fase I, recidivaram parcialmente na Fase II, sem comprometer a correção da má oclusão. O tipo facial foi preservado.

Palavras-chave: Má oclusão de Angle Classe II. Ortopedia. Ortodontia.

${ }^{1} \mathrm{PhD}$ in Orthodontics, School of Dentistry, University of São Paulo (USP). ${ }^{2}$ Full professor, Department of Orthodontics, University of São Paulo (USP). ${ }^{3}$ Full professor, Department of Orthodontics, University of Santa Cecília (UNISANTA).

» The authors report no commercial, proprietary or financial interest in the products or companies described in this article.

» Patients displayed in this article previously approved the use of their facial and intraoral photographs.
How to cite this article: Vigorito FA, Dominguez GC, Aidar LAA. Dental and skeletal changes in patients with mandibular retrognathism following treatment with Herbst and pre-adjusted fixed appliance. Dental Press J Orthod. 2014 Jan-Feb;19(1):46-54. doi: http://dx.doi.org/10.1590/2176-9451.19.1.046-054.oar

Submitted: April 03, 2012 - Revised and accepted: March 03, 2013

Contact address: Gladys Cristina Dominguez

Rua Dr. Alceu de Campos Rodrigues, 247 - Vila Nova Conceição

São Paulo/SP - Brazil

CEP: 04.544-000 - E-mail: gcdrodri@usp.br 


\section{INTRODUCTION}

Growing patients with Class II malocclusion and mandibular retrognathism may be treated with a variety of techniques, as described in the literature. Some of the techniques include treatment performed with an orthopedic phase employing appliances such as the Herbst. This treatment has been widely studied by Pancherz ${ }^{1-4}$ and other researchers ${ }^{5-22}$ who took several aspects into consideration and revealed that this type of treatment not only represents an alternative to the correction of Class II malocclusion, but also preserves the stomatognathic system. However, with regard to Brazilian individuals, these results are questioned: Are treatment effects skeletal or dentoalveolar? Is the mandibular growth curve modified when stimulated by the Herbst appliance? Are the obtained results lost after the appliance is removed? The complexity of clarifying the referred doubts lays in the difficulty of performing longitudinal studies in homogeneous casuistries. With a view to eliminating the tendency towards including only successful cases and, thus, confuse the results, the ideal would be that prospective studies were conducted with groups of consecutive patients. From this point of view, in 2007, a study ${ }^{23}$ was carried out to assess and compare, in patients treated during growth spurt, the dentoskeletal changes observed in the Herbst active phase and during a period of same duration after the appliance had been removed. The obtained results were the motivation to perform the present study which aims at assessing full treatment performed in adolescents in two phases: phase I - orthopedic with Herbst appliance and phase II - orthodontic with pre-adjusted fixed appliance.

\section{MATERIAL AND METHODS}

The sample comprised 17 Brazilian adolescent patients (12 men and 5 women), with mean age of 12 years and 4 months \pm 1 year and 2 months, and bone age corresponding to the growth spurt, as revealed by a hand-wrist radiograph. The patients were selected according to the following inclusion criteria: individuals with mandibular retrognathism and Angle Class II, division 1 malocclusion greater than half-cusp (> $3 \mathrm{~mm}$ ); individuals with overjet $>5 \mathrm{~mm}$ (permanent dentition); with model discrepancy under $4 \mathrm{~mm}$; with clinical recommendation for mandibular advancement to be performed with functional orthopedic appliance. Individuals with absence of teeth, dental fractures and dental caries were excluded. Treatment was carried out in two phases. Initially, the orthopedic phase (phase I) performed with Herbst functional orthopedic appliance placed onto acrylic splints associated with maxillary expansion screw. ${ }^{24}$ The objective was to correct the transversal discrepancy, ${ }^{25}$ activating the expansion screw during the first month of treatment. The appliance was made according to a wax bite registration obtained with $6 \mathrm{~mm}$ of initial advancement, and progressive advancements of $2 \mathrm{~mm}$ every 2 months, according to individual needs. This phase lasted for an average of $13.9 \pm 2.1$ months. Thereafter, the orthodontic phase (phase II) was performed with pre-adjusted fixed appliance and aimed at leveling and aligning the upper and lower teeth as well as at obtaining functional occlusion with adequate overjet and overbite. This phase lasted for 46 months.

Complete orthodontic documentation (panoramic and hand-wrist radiographs, lateral and frontal cephalograms; intra and extraoral photographs; study casts) was prepared for all patients at four stages: $\mathrm{T}_{1}$, immediately before treatment onset; $T_{2}$, after 13 months using the Herbst appliance, which represented the end of phase I; $\mathrm{T}_{3}, 13$ months after phase II or orthodontic phase had begun; and $\mathrm{T}_{4}$, phase II completion, totalizing a period of 33 months. All 68 lateral cephalograms were manually traced by the same operator at monthly intervals. They were analyzed with regard to the cephalometric variables of sagittal changes analysis ( $\mathrm{SO}$-analysis) suggested by Pancherz ${ }^{4}$ (Figs 1 and 2).

Patients' guardians signed an informed consent form, agreeing with all stages of the study and the posterior disclosure of results. The project was approved by the Institutional Review Board of the School of Dentistry/ USP and registered under protocol 109/06.

\section{STATISTICAL ANALYSIS}

Method error assessment (Dahlberg ${ }^{26}$ ) was performed in $11.8 \%$ of the sample.

The values of each measure and the relation of each moment assessed by means and standard deviations were expressed and compared to the measurements taken between the moments of assessment using the analysis of variance carried out with repeated measures. For measurements that presented statistically significant differences between the moments of assessment, Bonferroni multiple comparisons were performed. They revealed in which moments these differences occurred. The tests were performed with a significance level set at 5\%. 


\section{RESULTS}

For a better understanding of the characteristics of each moment of growth (Fig 2) and the differences between them, the results are presented in three tables. Table 1 presents the measures, the relation between measurements at each moment of assessment and the result of the analysis of variance.

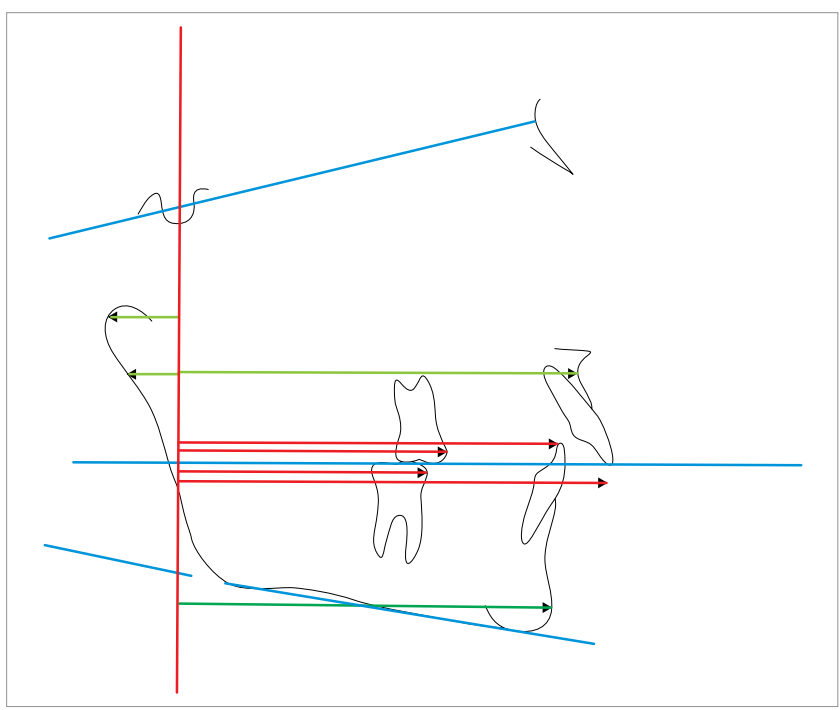

Figure 1 - Analysis of sagittal changes (SO-analysis) of Pancherz.
The results of Bonferroni multiple comparisons are presented in Table 2, whereas the results presenting differences in the relation between measures are shown in Table 3.

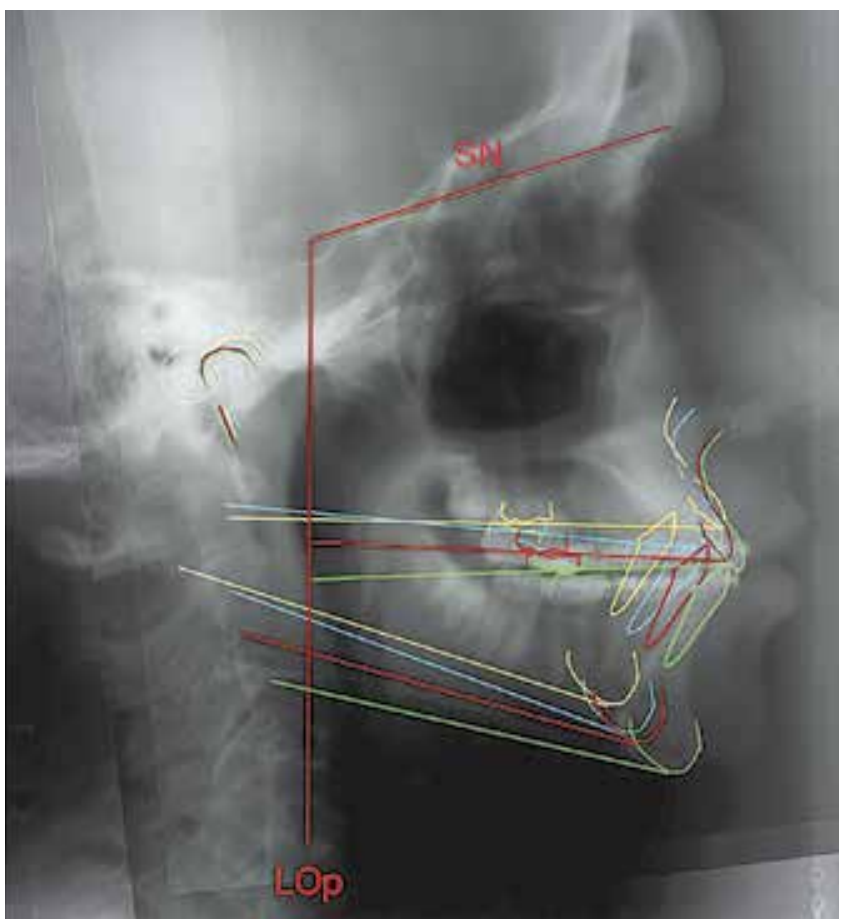

Figure 2 - Superimposition of tracings (according to analysis of Pancherz ${ }^{4}$ ), of one of the patients from the sample, in all four observation stages: $T_{1}=$ yellow, $T_{2}=$ blue, $T_{3}=$ red and $T_{4}=$ green

Table 1 - Measures and relations between values obtained at each moment of assessment and result of the analysis of variance.

\begin{tabular}{|c|c|c|c|c|c|c|}
\hline \multirow{3}{*}{ Variable } & \multicolumn{2}{|c|}{ Orthopedic phase } & \multicolumn{2}{|c|}{ Orthodontic phase } & \multirow{3}{*}{$\mathbf{N}$} & \multirow{3}{*}{$\mathbf{p}$} \\
\hline & $\mathrm{T}_{1}$ & $\mathrm{~T}_{2}$ & $T_{3}$ & $\mathrm{~T}_{4}$ & & \\
\hline & Mean \pm S.D. & Mean \pm S.D. & Mean \pm S.D. & Mean \pm S.D. & & \\
\hline SN.PM & $32.59 \pm 5.42$ & $32.56 \pm 5.59$ & $31.88 \pm 5.36$ & $32.03 \pm 6.26$ & 17 & 0.439 \\
\hline ui/Lop & $90.77 \pm 5.18$ & $90.47 \pm 6.55$ & $92.15 \pm 6.78$ & $93.79 \pm 6.28$ & 17 & $<0.001$ \\
\hline li/Lop & $81.62 \pm 5.95$ & $87.82 \pm 6.50$ & $87.97 \pm 6.60$ & $90.06 \pm 6.20$ & 17 & $<0.001$ \\
\hline um/Lop & $57.12 \pm 4.31$ & $57.21 \pm 5.02$ & $59.56 \pm 4.91$ & $62.35 \pm 5.45$ & 17 & $<0.001$ \\
\hline Im/Lop & $55.53 \pm 4.70$ & $61.32 \pm 5.24$ & $62.59 \pm 5.14$ & $65.59 \pm 5.61$ & 17 & $<0.001$ \\
\hline ss/Lop & $81.24 \pm 3.47$ & $82.50 \pm 3.94$ & $83.71 \pm 4.06$ & $84.24 \pm 4.40$ & 17 & $<0.001$ \\
\hline $\mathrm{pg} / \mathrm{Lop}$ & $83.15 \pm 5.30$ & $87.59 \pm 5.85$ & $88.59 \pm 6.04$ & $91.68 \pm 6.19$ & 17 & $<0.001$ \\
\hline $\mathrm{ar} / \mathrm{Lop}$ & $10.59 \pm 3.73$ & $10.24 \pm 3.70$ & $10.44 \pm 4.12$ & $9.88 \pm 4.14$ & 17 & 0.241 \\
\hline co/Lop & $12.94 \pm 3.62$ & $12.91 \pm 3.58$ & $13.29 \pm 3.63$ & $13.56 \pm 4.08$ & 17 & 0.319 \\
\hline SN.LO & $20.29 \pm 3.72$ & $23.15 \pm 4.63$ & $20.79 \pm 4.47$ & $19.06 \pm 4.72$ & 17 & $<0.001$ \\
\hline ui/Lop-li/Lop & $9.15 \pm 2.74$ & $2.65 \pm 1.23$ & $4.18 \pm 1.20$ & $3.74 \pm 0.90$ & 17 & $<0.001$ \\
\hline um/Lop-Im/Lop & $1.59 \pm 1.61$ & $-4.12 \pm 2.10$ & $-3.03 \pm 1.58$ & $-3.24 \pm 1.15$ & 17 & $<0.001$ \\
\hline pg/Lop+ar/Lop & $93.74 \pm 5.18$ & $97.82 \pm 5.76$ & $99.03 \pm 6.74$ & $101.56 \pm 7.66$ & 17 & $<0.001$ \\
\hline $\mathrm{pg} / \mathrm{Lop}+\mathrm{co} / \mathrm{Lop}$ & $96.09 \pm 5.12$ & $100.50 \pm 5.69$ & $101.88 \pm 6.62$ & $105.24 \pm 7.95$ & 17 & $<0.001$ \\
\hline ui/Lop-ss/Lop & $9.53 \pm 2.70$ & $7.97 \pm 3.12$ & $8.44 \pm 3.28$ & $9.56 \pm 2.93$ & 17 & 0.022 \\
\hline li/Lop-pg/Lop & $-1.53 \pm 5.83$ & $0.24 \pm 5.86$ & $-0.62 \pm 5.61$ & $-1.62 \pm 5.63$ & 17 & 0.031 \\
\hline um/Lop-ss/Lop & $-24.12 \pm 2.24$ & $-25.29 \pm 2.30$ & $-24.15 \pm 2.18$ & $-21.88 \pm 2.71$ & 17 & $<0.001$ \\
\hline Im/Lop-pg/Lop & $-27.62 \pm 3.74$ & $-26.26 \pm 4.20$ & $-26.00 \pm 4.46$ & $-26.09 \pm 4.92$ & 17 & 0.008 \\
\hline
\end{tabular}


Table 2 - Result of Bonferroni multiple comparisons for measurements that presented differences during treatment

\begin{tabular}{|c|c|c|c|c|c|c|}
\hline \multirow{2}{*}{ Variable } & \multirow{2}{*}{ Comparison } & \multirow{2}{*}{ Mean difference } & \multirow{2}{*}{ Standard error } & \multirow{2}{*}{$\mathbf{p}$} & \multicolumn{2}{|c|}{ Cl (95\%) } \\
\hline & & & & & Lower & Upper \\
\hline \multirow{6}{*}{ ui/Lop } & $T_{1}-T_{2}$ & 0.29 & 0.56 & $>0.999$ & -1.40 & 1.99 \\
\hline & $T_{1}-T_{3}$ & -1.38 & 0.76 & 0.516 & -3.66 & 0.89 \\
\hline & $T_{1}-T_{4}$ & -3.03 & 0.70 & 0.003 & -5.14 & -0.92 \\
\hline & $T_{2}-T_{3}$ & -1.68 & 0.49 & 0.020 & -3.14 & -0.21 \\
\hline & $T_{2}-T_{4}$ & -3.32 & 0.73 & 0.002 & -5.51 & -1.14 \\
\hline & $T_{3}-T_{4}$ & -1.65 & 0.52 & 0.034 & -3.20 & -0.10 \\
\hline \multirow{6}{*}{ li/Lop } & $T_{1}-T_{2}$ & -6.21 & 0.48 & $<0.001$ & -7.66 & -4.75 \\
\hline & $T_{1}-T_{3}$ & -6.35 & 0.65 & $<0.001$ & -8.30 & -4.41 \\
\hline & $T_{1}-T_{4}$ & -8.44 & 0.86 & $<0.001$ & -11.01 & -5.87 \\
\hline & $T_{2}-T_{3}$ & -0.15 & 0.56 & $>0.999$ & -1.83 & 1.54 \\
\hline & $T_{2}-T_{4}$ & -2.24 & 0.79 & 0.072 & -4.61 & 0.14 \\
\hline & $T_{3}-T_{4}$ & -2.09 & 0.59 & 0.016 & -3.86 & -0.31 \\
\hline \multirow{6}{*}{ um/Lop } & $T_{1}-T_{2}$ & -0.09 & 0.40 & $>0.999$ & -1.29 & 1.11 \\
\hline & $T_{1}-T_{3}$ & -2.44 & 0.44 & $<0.001$ & -3.75 & -1.13 \\
\hline & $T_{1}-T_{4}$ & -5.24 & 0.74 & $<0.001$ & -7.45 & -3.02 \\
\hline & $T_{2}-T_{3}$ & -2.35 & 0.37 & $<0.001$ & -3.46 & -1.25 \\
\hline & $T_{2}-T_{4}$ & -5.15 & 0.85 & $<0.001$ & -7.70 & -2.59 \\
\hline & $T_{3}-T_{4}$ & -2.79 & 0.65 & 0.003 & -4.74 & -0.85 \\
\hline \multirow{6}{*}{ Im/Lop } & $T_{1}-T_{2}$ & -5.79 & 0.50 & $<0.001$ & -7.29 & -4.30 \\
\hline & $T_{1}-T_{3}$ & -7.06 & 0.57 & $<0.001$ & -8.76 & -5.36 \\
\hline & $T_{1}-T_{4}$ & -10.06 & 1.02 & $<0.001$ & -13.13 & -6.99 \\
\hline & $T_{2}-T_{3}$ & -1.27 & 0.45 & 0.073 & -2.61 & 0.08 \\
\hline & $T_{2}-T_{4}$ & -4.27 & 0.98 & 0.003 & -7.22 & -1.31 \\
\hline & $T_{3}-T_{4}$ & -3.00 & 0.69 & 0.003 & -5.07 & -0.93 \\
\hline \multirow{6}{*}{ ss/Lop } & $T_{1}-T_{2}$ & -1.27 & 0.30 & 0.004 & -2.17 & -0.36 \\
\hline & $T_{1}-T_{3}$ & -2.47 & 0.45 & $<0.001$ & -3.82 & -1.12 \\
\hline & $T_{1}-T_{4}$ & -3.00 & 0.66 & 0.002 & -4.99 & -1.01 \\
\hline & $T_{2}-T_{3}$ & -1.21 & 0.37 & 0.032 & -2.33 & -0.08 \\
\hline & $T_{2}-T_{4}$ & -1.74 & 0.64 & 0.094 & -3.67 & 0.20 \\
\hline & $T_{3}-T_{4}$ & -0.53 & 0.43 & $>0.999$ & -1.81 & 0.75 \\
\hline \multirow{6}{*}{ pg/Lop } & $T_{1}-T_{2}$ & -4.44 & 0.53 & $<0.001$ & -6.02 & -2.86 \\
\hline & $T_{1}-T_{3}$ & -5.44 & 0.71 & $<0.001$ & -7.57 & -3.31 \\
\hline & $\mathrm{T}_{1}-\mathrm{T}_{4}$ & -8.53 & 1.11 & $<0.001$ & -11.86 & -5.20 \\
\hline & $T_{2}-T_{3}$ & -1.00 & 0.46 & 0.280 & -2.40 & 0.40 \\
\hline & $T_{2}-T_{4}$ & -4.09 & 1.00 & 0.005 & -7.10 & -1.08 \\
\hline & $T_{3}-T_{4}$ & -3.09 & 0.70 & 0.003 & -5.19 & -0.99 \\
\hline \multirow{6}{*}{ SN.LO } & $T_{1}-T_{2}$ & -2.85 & 0.85 & 0.023 & -5.40 & -0.31 \\
\hline & $T_{1}-T_{3}$ & -0.50 & 0.75 & $>0.999$ & -2.76 & 1.76 \\
\hline & $T_{1}-T_{4}$ & 1.24 & 0.78 & 0.801 & -1.12 & 3.59 \\
\hline & $T_{2}-T_{3}$ & 2.35 & 0.32 & $<0.001$ & 1.39 & 3.32 \\
\hline & $T_{2}-T_{4}$ & 4.09 & 0.86 & 0.001 & 1.51 & 6.67 \\
\hline & $T_{3}-T_{4}$ & 1.74 & 0.61 & 0.068 & -0.09 & 3.56 \\
\hline
\end{tabular}


Table 3 - Result of Bonferroni multiple comparisons for relations between measures that presented differences during treatment.

\begin{tabular}{|c|c|c|c|c|c|c|}
\hline \multirow{2}{*}{ Variable } & \multirow{2}{*}{ Comparison } & \multirow{2}{*}{ Mean difference } & \multirow{2}{*}{ Standard error } & \multirow{2}{*}{$\mathbf{p}$} & \multicolumn{2}{|c|}{$\mathrm{Cl}(95 \%)$} \\
\hline & & & & & Lower & Upper \\
\hline \multirow{6}{*}{ ui/Lop-li/Lop } & $T_{1}-T_{2}$ & 6.50 & 0.71 & $<0.001$ & 4.37 & 8.64 \\
\hline & $T_{1}-T_{3}$ & 4.97 & 0.78 & $<0.001$ & 2.64 & 7.31 \\
\hline & $T_{1}-T_{4}$ & 5.41 & 0.75 & $<0.001$ & 3.16 & 7.66 \\
\hline & $T_{2}-T_{3}$ & -1.53 & 0.49 & 0.041 & -3.01 & -0.05 \\
\hline & $T_{2}-T_{4}$ & -1.09 & 0.43 & 0.129 & -2.37 & 0.20 \\
\hline & $T_{3}-T_{4}$ & 0.44 & 0.30 & 0.963 & -0.46 & 1.34 \\
\hline \multirow{6}{*}{ um/Lop-Im/Lop } & $T_{1}-T_{2}$ & 5.71 & 0.47 & $<0.001$ & 4.30 & 7.11 \\
\hline & $T_{1}-T_{3}$ & 4.62 & 0.43 & $<0.001$ & 3.33 & 5.90 \\
\hline & $T_{1}-T_{4}$ & 4.82 & 0.40 & $<0.001$ & 3.61 & 6.03 \\
\hline & $T_{2}-T_{3}$ & -1.09 & 0.24 & 0.002 & -1.81 & -0.37 \\
\hline & $T_{2}-T_{4}$ & -0.88 & 0.47 & 0.482 & -2.30 & 0.54 \\
\hline & $T_{3}-T_{4}$ & 0.21 & 0.33 & $>0.999$ & -0.78 & 1.19 \\
\hline \multirow{6}{*}{ pg/Lop+ar/Lop } & $T_{1}-T_{2}$ & -4.09 & 0.44 & $<0.001$ & -5.42 & -2.75 \\
\hline & $T_{1}-T_{3}$ & -5.29 & 0.69 & $<0.001$ & -7.36 & -3.23 \\
\hline & $T_{1}-T_{4}$ & -7.82 & 1.05 & $<0.001$ & -10.98 & -4.67 \\
\hline & $T_{2}-T_{3}$ & -1.21 & 0.56 & 0.286 & -2.90 & 0.49 \\
\hline & $T_{2}-T_{4}$ & -3.74 & 0.96 & 0.008 & -6.61 & -0.86 \\
\hline & $T_{3}-T_{4}$ & -2.53 & 0.56 & 0.002 & -4.22 & -0.84 \\
\hline \multirow{6}{*}{$\mathrm{pg} / \mathrm{Lop}+\mathrm{co} / \mathrm{Lop}$} & $T_{1}-T_{2}$ & -4.41 & 0.37 & $<0.001$ & -5.52 & -3.30 \\
\hline & $T_{1}-T_{3}$ & -5.79 & 0.61 & $<0.001$ & -7.63 & -3.96 \\
\hline & $T_{1}-T_{4}$ & -9.15 & 1.12 & $<0.001$ & -12.52 & -5.77 \\
\hline & $T_{2}-T_{3}$ & -1.38 & 0.51 & 0.096 & -2.93 & 0.16 \\
\hline & $T_{2}-T_{4}$ & -4.74 & 1.06 & 0.002 & -7.91 & -1.56 \\
\hline & $T_{3}-T_{4}$ & -3.35 & 0.71 & 0.001 & -5.50 & -1.21 \\
\hline \multirow{6}{*}{ ui/Lop-ss/Lop } & $T_{1}-T_{2}$ & 1.56 & 0.49 & 0.035 & 0.08 & 3.03 \\
\hline & $T_{1}-T_{3}$ & 1.09 & 0.71 & 0.857 & -1.04 & 3.21 \\
\hline & $T_{1}-T_{4}$ & -0.03 & 0.70 & $>0.999$ & -2.12 & 2.06 \\
\hline & $T_{2}-T_{3}$ & -0.47 & 0.44 & $>0.999$ & -1.80 & 0.86 \\
\hline & $T_{2}-T_{4}$ & -1.59 & 0.59 & 0.095 & -3.36 & 0.18 \\
\hline & $T_{3}-T_{4}$ & -1.12 & 0.46 & 0.155 & -2.49 & 0.25 \\
\hline \multirow{6}{*}{ li/Lop-pg/Lop } & $T_{1}-T_{2}$ & -1.77 & 0.44 & 0.006 & -3.08 & -0.45 \\
\hline & $T_{1}-T_{3}$ & -0.91 & 0.76 & $>0.999$ & -3.20 & 1.37 \\
\hline & $T_{1}-T_{4}$ & 0.09 & 0.77 & $>0.999$ & -2.24 & 2.41 \\
\hline & $T_{2}-T_{3}$ & 0.85 & 0.59 & $>0.999$ & -0.92 & 2.63 \\
\hline & $T_{2}-T_{4}$ & 1.85 & 0.66 & 0.076 & -0.13 & 3.84 \\
\hline & $T_{3}-T_{4}$ & 1.00 & 0.37 & 0.092 & -0.11 & 2.11 \\
\hline \multirow{6}{*}{ um/Lop-ss/Lop } & $T_{1}-T_{2}$ & 1.18 & 0.30 & 0.008 & 0.27 & 2.09 \\
\hline & $T_{1}-T_{3}$ & 0.03 & 0.39 & $>0.999$ & -1.13 & 1.19 \\
\hline & $T_{1}-T_{4}$ & -2.24 & 0.45 & 0.001 & -3.60 & -0.88 \\
\hline & $T_{2}-T_{3}$ & -1.15 & 0.33 & 0.019 & -2.14 & -0.15 \\
\hline & $T_{2}-T_{4}$ & -3.41 & 0.58 & $<0.001$ & -5.16 & -1.67 \\
\hline & $T_{3}-T_{4}$ & -2.27 & 0.58 & 0.008 & -4.02 & -0.51 \\
\hline \multirow{6}{*}{ Im/Lop-pg/Lop } & $T_{1}-T_{2}$ & -1.35 & 0.41 & 0.026 & -2.58 & -0.12 \\
\hline & $T_{1}-T_{3}$ & -1.62 & 0.53 & 0.045 & -3.21 & -0.03 \\
\hline & $T_{1}-T_{4}$ & -1.53 & 0.62 & 0.156 & -3.41 & 0.35 \\
\hline & $T_{2}-T_{3}$ & -0.27 & 0.26 & $>0.999$ & -1.05 & 0.52 \\
\hline & $T_{2}-T_{4}$ & -0.18 & 0.47 & $>0.999$ & -1.59 & 1.24 \\
\hline & $\mathrm{T}_{3}-\mathrm{T}_{4}$ & 0.09 & 0.35 & $>0.999$ & -0.97 & 1.15 \\
\hline
\end{tabular}




\section{DISCUSSION}

All patients that comprised this study presented, in $\mathrm{T}_{1}$, typical characteristics of Class II division 1 malocclusion, as confirmed by the initial cephalometric variables that describe the molar relationship (um/Lop - lm/Lop: $1.59 \pm 1.61 \mathrm{~mm}$ ) and the overjet (ui/Lop - li/Lop: $9.15 \pm 2.74 \mathrm{~mm}$ ). According to the inclusion criteria, all patients clinically presented mandibular retrognathism and accepted treatment that included mandibular advancement.

The results yielded by the present study are in agreement with previous studies that used similar methods. ${ }^{9,12,23,27}$ Both the maxilla (SS/Lop) and mandible (PPg/Lop) were anteriorly projected, but since mandibular growth increment was 3.5 times greater, there was a favorable sagittal maxillomandibular adjustment. In order to identify the contribution of mandibular growth, measurements of the absolute mandibular length $\left(\mathrm{pg} / \mathrm{Lop}{ }^{+} \mathrm{co} / \mathrm{Lop}\right.$ and $\left.\mathrm{pg} / \mathrm{Lop}+\mathrm{ar} / \mathrm{Lop}\right)$ were assessed and significant growth increment was observed, although the condylar (co/Lop) and articular (ar/Lop) points did not present any alterations.

The registered amount of skeletal growth allowed better a understanding of how the teeth varied in their sagittal spatial position. Overcorrection of the observed molar relationship (um/Lop-lm/Lop: $5.71 \mathrm{~mm}$ ) was due to the association between maintenance of upper molars position (um/Lop: -0.09) while the maxilla was anteriorly projected (SS/Lop: $-1.27 \mathrm{~mm}$ ), and mesialization of lower molars ( $\mathrm{lm} / \mathrm{Lop}:-5.79 \mathrm{~mm}$ ) along with mandibular anterior projection (pg/Lop: $-4.44 \mathrm{~mm}$ ). Overjet was significantly reduced from $9.5 \mathrm{~mm}$ to $2.65 \mathrm{~mm}$, as a result of mandibular anterior projection (pg/Lop: $-4.44 \mathrm{~mm}$ ) and buccal inclination of lower incisors in their bone base (li/Lop: $-6.21 \mathrm{~mm}$ ). The mechanical effect observed in the inclination of lower incisors restricts the recommendation of this type of therapy to individuals who do not present increased inclination at treatment onset.

The occlusal plane (SN.LO), which in the beginning presented a mean value that is typical of a mesofacial pattern $\left(32.59 \pm 5.42^{\circ}\right)$, was rotated clockwise $\left(2.85^{\circ}\right)$ by the presence of interocclusal acrylic splints. This might have caused the effect of molar intrusion, since, when the appliance was removed, an important posterior disocclusion was observed in all patients. This speculation can be done because, differently from the occlusal plane, the inclination of the mandibular plane (SN.PM) did not undergo any alterations, thus confirming that it was just a dentoalveolar effect and not a skeletal one, therefore, the facial type did not change.

In the following 13 months after the Herbst appliance had been removed, which corresponded to orthodontic treatment onset $\left(\mathrm{T}_{2}-\mathrm{T}_{3}\right)$, the maxilla continued to be anteriorly projected (ss/Lop: $-1.21 \mathrm{~mm}$ ), whereas mandibular projection was little significant (pg/Lop: $-1 \mathrm{~mm}$ ). It was observed that partial recurrence of molar relationship (um/Lop-lm/Lop: $-1.09 \mathrm{~mm}$ ) occurred as a result of mesialization of upper molars (um/Lop-ss/Lop: $-1.15 \mathrm{~mm}$ ) along with non-significant mesialization of lower molars ( $1 \mathrm{~m} /$ Loppg/Lop: -027). However, considering that a relation of overcorrection of molar relationship was observed in $\mathrm{T}_{2}$ ( $\mathrm{um} / \mathrm{Lop}-\mathrm{lm} / \mathrm{Lop}:-4.12 \mathrm{~mm}$ ), this recurrence was favorable to adjust the molars in Class I relation (um/Lop-lm/Lop: -3.03 mm). Additionally, there was a partial recurrence of $1.53 \mathrm{~mm}$ in overjet (ui/Lop-li/Lop) as a result of differential growth of the maxilla, which led the upper incisors to occupy a more anterior spatial position (is/Lop: $-1.68 \mathrm{~mm}$ ). This could not have been due to the insignificant uprighting of lower incisors (li/Lop: $-0.15 \mathrm{~mm}$ ) because, in this case, they did not change their position (li/Lop-pg/Lop: $0.85 \mathrm{~mm}$ ).

The occlusal plane (SL.LO) rotated counterclockwise, since, from $T_{2}$ to $T_{3}$, with the removal of the Herbst appliance, the molars were free from the interocclusal splints and, additionally, were actively leveled to the orthodontic appliance, restoring the vertical spatial position that they presented at treatment onset. These data corroborate data found in the literature,, 910 thus confirming that this movement happened without affecting the inclination of the mandibular plane $(\mathrm{SN}-$ PM), therefore, with preservation of facial type.

The complementary assessment carried out in this study, between the thirteen-month interval after removal of the Herbst appliance and the end of the active orthodontic treatment $\left(\mathrm{T}_{3}-\mathrm{T}_{4}\right)$, showed that, while the maxilla was not significantly anteriorly projected (SS/Lop: $-0.53 \mathrm{~mm}$ ), the mandible resumed its growth (pg/Lop: $-3.09 \mathrm{~mm})$, significantly anteriorly projecting itself. Molar relationship (um/Lop-lm/ Lop: $0.21 \mathrm{~mm}$ ) remained stable in Class I. Moreover, no expressive changes were observed for the overjet (ui/Lop-li/Lop: 0.44mm). 
Nevertheless, when analyzing the maintenance of dental stability, during a period in which there was significant expression of mandibular growth and absence of significant maxillary growth, it could be observed that tooth movement was compensatory, maintaining both molar and overjet relations. While the upper incisors (ui/Lop: $-1.65 \mathrm{~mm}$ ) and the upper molars (um/Lop: $-2.79 \mathrm{~mm}$ ) were anteriorly projected in the absence of significant maxillary growth (ss/Lop: $-053 \mathrm{~mm}$ ), the lower incisors (li/Lop: $-2.09 \mathrm{~mm}$ ) and lower molars ( $1 \mathrm{~m} /$ Lop:-3 $\mathrm{mm}$ ) were also spatially anteriorly projected, however, in association with significant mandibular growth (pg/Lop: $-3.09 \mathrm{~mm})$. Thus, it can be concluded by means of the differential calculus (dental movement minus skeletal movement) that only the upper molars had a significant movement of mesialization, regardless of the growth of its bone base (um/Lop-ss/Lop: -2.27 mm). This movement was necessary to maintain Class I molar relationship. The occlusal plane remained stable (SN.LO: $1.74^{\circ}$ ). This fact can be explained because in $\mathrm{T}_{3}$, the molars already presented interocclusal contact and there were no additional vertical movements until $\mathrm{T}_{4}$. The mandibular plane remained unchanged, revealing a uniform behavior during the entire treatment, thus, preserving facial type.

When considering the series of changes observed from the beginning to the end of treatment $\left(\mathrm{T}_{1}-\mathrm{T}_{4}\right)$, it is verified that out of the total of maxillary anterior projection $(3 \mathrm{~mm}), 42 \%$ happened during the orthopedic phase $\left(\mathrm{T}_{1}-\mathrm{T}_{2}\right)$ and $58 \%$ during the orthodontic phase $\left(\mathrm{T}_{2}-\mathrm{T}_{4}\right)$, of which the most part $(40.3 \%)$ happened during the first 13 months $\left(\mathrm{T}_{2}-\mathrm{T}_{3}\right)$ and the rest (17.7\%), an insignificant increase, between $\mathrm{T}_{3}$ and $\mathrm{T}_{4}$. As shown in Tables 1 to 3, the mandibular anterior displacements ( $\mathrm{Pg} / \mathrm{Lop})$ were compatible to the corresponding increment of the mandibular absolute growth $(\mathrm{Pg} / \mathrm{Lop}+\mathrm{ar} /$ Lop and $\mathrm{Pg} / \mathrm{Lop}+\mathrm{co} / \mathrm{Lop})$. When analyzing the variable $\mathrm{Pg} / \mathrm{Lop}+\mathrm{co} / \mathrm{Lop}$, it is verified that $48.2 \%$ of mandibular growth happened during the 13 months of the orthopedic phase $\left(T_{1}-T_{2}\right)$ as a response to the stimulus provided by the Herbst appliance, in a period when the potential growth was intense; whereas 51.8\% happened during the orthodontic phase $\left(\mathrm{T}_{2}-\mathrm{T}_{4}\right)$. However, it must be emphasized that during the 13 months after the Herbst appliance was removed $\left(\mathrm{T}_{2}-\mathrm{T}_{3}\right)$, there was growth deceleration, with slight, non-significant growth increment (15.1\%) and, therefore, without anterior projec- tion. Significant growth was soon resumed, expressing the remaining $36.7 \%$ in the following months until $\mathrm{T}_{4}$. This type of response agrees with previous studies. ${ }^{4,9}$ It was very important to assess the amount of growth during the orthodontic phase $\left(\mathrm{T}_{2}-\mathrm{T}_{4}\right)$ as proposed in this study. Moreover, dividing observation into two periods, $\mathrm{T}_{2}-\mathrm{T}_{3}$ (13 months) and $\mathrm{T}_{3}-\mathrm{T}_{4}$ (33 months), was important to understand whether or not the curve of mandibular growth could modify its usual course before the stimulus given by the use of the Herbst appliance. Franchi et $\mathrm{a}^{28}$ claim that mandibular growth follows the physical growth spurt and it is characterized by a gradual increase in the amount of increments until it reaches its maximum, when the greatest amount of growth is expressed. Afterwards, it gradually decelerates again, however, linearly, until growth is complete. In the present study, it was observed that during the 13 months of stimulus $\left(\mathrm{T}_{1}-\mathrm{T}_{2}\right)$ provided by the Herbst appliance, the increments were intense. Nevertheless, a deceleration in the following 13 months $\left(\mathrm{T}_{2}-\mathrm{T}_{3}\right)$, and then, a resumption of growth $\left(\mathrm{T}_{3}-\mathrm{T}_{4}\right)$, explain that the growth verified between $T_{1}$ and $T_{2}$ represents the favorable expression of the present growth potential, for being in its maximum (as revealed by the hand-wrist radiograph in $\mathrm{T}_{1}$ ), which is summed up to the anticipation of growth in the subsequent 13 months, which, without the use of the appliance, would not have manifested at that moment, thus, modifying the behavior of the descendant curve of growth spurt in adolescence.

As for growth complexity and mandibular spatial projection in the face, our results can be explained by those observed by Pancherz et $\mathrm{al}^{29}$ who assessed the "effective condylar growth" and its influence over the spatial position of the symphysis in the face. Their findings reveal that condylar growth triplicated during the active phase of six months in which the Herbst appliance was used, decelerated in a similar period after the removal of the appliance, and soon resumed its normal growth in the subsequent 30 months. Comparison between total mandibular and maxillary projection, from $\mathrm{T}_{1}$ to $\mathrm{T}_{4}$, revealed that the mandible (pg/Lop: $8.47 \mathrm{~mm}$ ) was projected 2.8 times more than the maxilla (ss/Lop: $3 \mathrm{~mm}$ ), a fact that favored sagittal maxillomandibular adjustment.

With regard to dentoalveolar correction of Class II malocclusion, a favorable response was observed between $\mathrm{T}_{1}$ and $\mathrm{T}_{4}$, i.e., Class II molar relationship and the 
increase in overjet that patients presented at treatment onset were ideally corrected. In $\mathrm{T}_{4}$, all of them showed characteristics of normal occlusion, with good molar relationship and adequate overjet, thus, achieving the purpose of the treatment. In order to produce such results, treatment evolved from sagittal overcorrection of molar relationship, which was associated with great reduction in overjet during the 13-month orthopedic phase; partially relapsed at the beginning of the orthodontic phase and became stable in the following 33 months until the end of the treatment.

Based on the aforementioned observations, it is important to emphasize that: First, the recurrence of the overcorrected molar relationship between $\mathrm{T}_{2}$ and $\mathrm{T}_{3}$ was necessary for molars to obtain cusp-to-fossa relationship instead of cusp-to-cusp, which probably contributed to offer the stability observed in the subsequent period. Additionally, despite being significant, the degree of overjet relapse registered between $T_{2}$ and $T_{3}$, did not prevent the values from being within the clinical parameters of normality by the end of the treatment. The second aspect is with regard to the stability observed in $\mathrm{T}_{3}$ and $\mathrm{T}_{4}$, a period of 33 months. The advantage of lasting nearly two times longer than each previous period allowed the stability of results to be assessed.

Clockwise rotation of the occlusal plane was significant during the orthopedic phase $\left(\mathrm{T}_{1}-\mathrm{T}_{2}\right)$ and it happened as a result of the presence of interocclusal splints. In the subsequent phase $\left(\mathrm{T}_{2}-\mathrm{T}_{3}\right)$, it rotated counterclockwise, therefore, relapsing by the removal of the splints and active orthodontic leveling, thus, restoring intermaxillary occlusal contacts. This pattern of counterclockwise rotation continued in the following 33 months, however, insignificantly. As for the changes that occurred in opposite directions, the comparison between orthopedic and orthodontic phases reveal that they did not present any adverse clinical effect, since the changes occurred without influencing the inclination of the mandibular plane. On the other hand, the occlusal plane restored its initial inclination in $\mathrm{T}_{3}$ and remained stable until $\mathrm{T}_{4}$. The mandibular plane (SN.PM), which defines the facial type, was maintained in all periods of assessment, a fact that is favorable to the stability achieved in the long term, all of which agreed with other authors in the literature..$^{9,30}$

The size of the sample is a limitation of this study. However, it is of great value considering that it is a prospective study carried out with consecutive patients and that had never been performed with Brazilian patients. The results obtained from assessing these patients by means of the treatment protocol allowed us to visualize not only that the therapy applied was efficient, but also that the series of skeletal and dental changes observed did not cause a temporary impact, but an impact that is compatible with the conditions of stability in the long term. However, further studies are necessary to longitudinally assess the post-treatment phase. Finally, it is important to emphasize the undesirable effect that the use of the Herbst appliance can cause to individuals with increased buccal inclination of the lower incisors at treatment onset.

\section{CONCLUSIONS}

Based on the results of treatment of adolescents with Class II malocclusion and mandibular retrognathism performed in two phases (Herbst and pre-adjusted orthodontic appliance) it is reasonable to conclude that both skeletal and dental changes, when performed together, allowed the correction of the malocclusion. The mandible grew significantly more than the maxilla, which favored sagittal maxillomandibular adjustment. The dental changes (distalization of upper molars) that overcorrected the malocclusion in phase I partially relapsed in phase II, without compromising the correction of the malocclusion. The facial type was preserved. 
1. Pancherz $\mathrm{H}$. Treatment of Class II malocclusions by jumping the bite with the Herbst appliance. A cephalometric investigation. Am J Orthod.1979;76(4):423-42

2. Pancherz $\mathrm{H}$, Hansen $\mathrm{K}$. Occlusal changes during and after Herbst treatment: a cephalometric investigation. Eur J Orthod. 1986:8(4):215-28.

3. Pancherz $\mathrm{H}$, Fackel $U$. The skeletofacial growth pattern pre and postdentofacial orthopaedics. A long-term study of Class II malocclusions treated with the Herbst appliance. Eur J Orthod. 1990;12(2):209-18.

4. Pancherz H, Ruf S. The Herbst appliance. Research based clinical management. Quintessence; 2008. cap. 6, p. 43-6.

5. Hägg U, Pancherz $\mathrm{H}$. Dentofacial orthopaedics in relation to chronological age, growth period and skeletal development. An analysis of 72 male patients with Class II division 1 malocclusion treated with Herbst appliance. Eur J Orthod. 1988:10(3):169-76.

6. McNamara JA Jr, Howe RP, Dischinger TG. A comparison of the Herbst and Fränkel appliances in the treatment of Class II malocclusion. Am J Orthod Dentofacial Orthop. 1990;98(2):134-44

7. Schiavoni R, Grenga V, Macri V. Treatment of Class II high angle malocclusions with the Herbst appliance: a cephalometric investigation. Am J Orthod Dentofacial Orthop. 1992;102(5):393-409.

8. Windmiller EC. The acrylic-splint Herbst appliance: a cephalometric evaluation. Am J Orthod Dentofacial Orthop. 1993:104(1):73-84.

9. Lai M, McNamara JA Jr. An evaluation of two-phase treatment with the Herbst appliance and preadjusted edgewise therapy. Semin Orthod. 1998:4(1):46-58

10. Franchi L, Baccetti T, McNamara JA Jr. Treatment and posttreatment effects of acrylic splint Herbst appliance therapy. Am J Orthod Dentofacial Orthop. 1999:115(4):429-38.

11. Manfredi C, Cimino R, Trani A, Pancherz H. Skeletal changes of Herbst appliance therapy investigated with more conventional cephalometrics and European norms. Angle Orthod. 2001;71(3):170-6.

12. Schütz TCB, Vigorito JW, Rodrigues CRMD, Domínguez-Rodríguez GC. Avaliação cefalométrico-radiográfica das modificações dentoalveolares decorrentes do tratamento com o aparelho Herbst em adolescentes com maloclusão de Classe II, divisão 1a de Angle - Parte I. Ortodontia. 2002;35(4):22-34.

13. Schütz TCB, Vigorito JW, Domínguez-Rodríguez GC. Avaliação cefalométrico-radiográfica das modificações esqueléticas e do perfil facial decorrentes do tratamento com o aparelho Herbst em adolescentes com maloclusão de Classe II, divisão 1a de Angle - Parte II. Ortodontia. 2003:36(1):44-61.

14. Ruf S. Short and long-term effects of the Herbst appliance on temporomandibular joint function. Semin Orthod. 2003:9(1):74-86.

15. Schaefer AT, MCNamara JA Jr. Franchi L, Baccetti T. A cephalometric comparison of treatment with the Twin-block and stainless steel crown Herbst appliances followed by fixed appliance therapy. Am J Orthod Dentofacial Orthop. 2004;126(1):7-15.
16. VanLaecken R, Martin CA, Dischinger T, Razmus T, Ngan P. Treatment effects of the edgewise Herbst appliance: a cephalometric and tomographic investigation. Am J Orthod Dentofacial Orthop. 2006:130(5):582-93.

17. Ruf S, Pancherz H. Herbst/multibracket appliance treatment of Class II division 1 malocclusions in early and late adulthood. A prospective cephalometric study of consecutively treated subjects. Eur J Orthod 2006:76(2):352-60

18. Bock N, Pancherz H. Herbst treatment of Class II division 1 malocclusions in retrognathic and prognathic facial types. Angle Orthod. 2006;76(6):930-41.

19. Aidar LA, Dominguez GC, Abrahão M, Yamashita HK, Vigorito JW. Effects of Herbst appliance treatment on temporomandibular joint disc position and morphology: a prospective magnetic resonance imaging study. Am J Orthod Dentofacial Orthop. 2009;136(3):412-24

20. Aidar LA, Dominguez GC, Yamashita HK, Abrahão M.Changes in temporomandibular joint disc position and form following Herbst and fixed orthodontic treatment. Angle Orthod. 2010;80(5):843-52.

21. Siara-Olds NJ, Pangrazio-Kulbersh V, Berger J, Bayirli B. Long-term dentoskeletal changes with the Bionator, Herbst, Twin Block, and MARA Functional Appliances. Angle Orthod. 2010;80(1):18-29.

22. Schütz TC, Dominguez GC, Hallinan MP, Cunha TC, Tufik S. Class II correction improves nocturnal breathing in adolescents. Angle Orthod. 2011:81(2):222-8

23. Vigorito FA, Domínguez GC. Comparação dos efeitos dento-esqueléticos decorrentes do tratamento realizado em duas fases (com aparelho de Herbst e aparelho fixo pré-ajustado) em adolescentes com retrognatismo mandibular. Ortodontia. 2007:40(4):263-70.

24. Howe RP, MCNamara JA Jr. Clinical management of the bonded Herbst appliance. J Clin Orthod. 1983:17(7):456-63.

25. Tollero I, Baccetti T, Franchi L, Tanasescu CD. Role of the posterior transverse interarch discrepancy in Class II, division 1 malocclusion during the mixed dentition phase. Am J Orthod Dentofacial Orthop. 1996:110(4):417-22.

26. Houston WJB. The analysis of errors in orthodontic measurements. Am J Orthod. 1983:83(5):383-90

27. Flores-Mir C, Ayeh, Goswani A, Charkhandeh S. Skeletal and dental changes in class II division 1 malocclusions treated with Splint-Type Herbst appliances: a systematic review. Angle Orthod. 2007:77(2):376-81.

28. Franchi L, Baccetti T, McNamara JA. Mandibular growth as related to cervical vertebral maturation and body height. Am J Orthod Dentofacial Orthop. 2000:118(3):335-40

29. Pancherz H, Ruf S, Kohlhas P. Effective condylar growth and chin position changes in Herbst treatment: a cephalometric roentgenographic longterm study. Am J Orthod Dentofacial Orthop. 1998;114(4):437-46.

30. Ruf S, Pancherz $\mathrm{H}$. The effect of Herbst appliance on the mandibular plane: a cephalometric roentgenographic study. Am J Orthod Dentofacial Orthop. 1996:110(2):225-9. 